\title{
Jxc1/Sobp, Encoding a Nuclear Zinc Finger Protein, Is Critical for Cochlear Growth, Cell Fate, and Patterning of the Organ of Corti
}

\author{
Zheng Chen, ${ }^{1}$ Mireille Montcouquiol,,${ }^{2,3}$ Rene Calderon, ${ }^{1}$ Nancy A. Jenkins, ${ }^{4}$ Neal G. Copeland, ${ }^{4}$ Matthew W. Kelley, ${ }^{2}$ and \\ Konrad Noben-Trauth ${ }^{1}$ \\ Sections on ${ }^{1}$ Neurogenetics and ${ }^{2}$ Developmental Neuroscience, Laboratory of Molecular Biology, National Institute on Deafness and Other Communication \\ Disorders, National Institutes of Health, Rockville, Maryland 20850, ${ }^{3}$ Inserm U862, Avenir, Developmental Neuroscience, 33077 Bordeaux Cedex, France, \\ and ${ }^{4}$ Mouse Cancer Genetics Program, National Cancer Institute, Frederick, Maryland 21702
}

The mouse cochlea emerges from the ventral pole of the otocyst to form a one and three-quarter coil. Little is known about the factors that control the growth of the cochlea. Jackson circler $(j c)$ is a recessive mutation causing deafness resulting from a growth arrest of the cochlea duct at day 13.5 of embryonic development. Here, we identify the vertebrate homolog of the Drosophila Sobp (sine oculis-binding protein) gene (named $J x c 1$ ) in the $j c$ locus. Jxc1 encodes a nuclear protein that has two FCS-type zinc finger domains (PS51024) and bears nuclear localization signals and highly conserved sequence motifs. Transiently expressed wild-type protein is targeted to the nucleus, but mutant isoforms were mislocalized in the cytoplasm. In $j c$ mutants, the cellular patterning of the organ of Corti is severely disrupted, exhibiting supernumerary hair cells at the apex, showing mirror-image duplications of tunnel of Corti and inner hair cells, and expressing ectopic vestibular-like hair cells within Kölliker's organ. $J x c 1$ mRNA was detected in inner ear sensory hair cells, supporting cells, and the acoustic ganglia. Expression was also found in the developing retina, olfactory epithelium, trigeminal ganglion, and hair follicles. Collectively, our data support a role for $J x c 1$ in controlling a critical step in cochlear growth, cell fate, and patterning of the organ of Corti.

Key words: cochlea dysplasia; organ of Corti; FCS zinc finger; Kölliker’s organ; Jackson circler; Jxc1

\section{Introduction}

The development of the mouse cochlea follows a set of timely regulated processes, one of which is the controlled growth of the cochlea duct. This elongation occurs between embryonic day 11.5 (E11.5) and E17 and is accompanied by cellular rearrangements during which a disordered array of postmitotic cells is transformed into a highly organized mosaic cell pattern (Morsli et al., 1998; Barald and Kelley, 2004). Although the fate and specification of sensory and supporting cells in the organ of Corti are intensely studied, there are still large gaps in our understanding

\footnotetext{
Received March 25, 2008; revised May 2, 2008; accepted May 12, 2008.

This work was supported by the Division of Intramural Research at National Institutes of Health (NIH) (K.N.-T., M.W.K., N.A.J., N.G.C.) and by grants from Institut National de la Santé et de la Recherche Médicale, Fondation pour la Recherche Médicale, and Région Aquitaine and Direction Generale pour la Sante (M.M.). We thank Jimmy Fiallos for maintenance of the mouse colonies, Harold Neely for help with histology, and Doris Wu for help with in situ hybridization. Lfng was kindly provided by Doris Wu (National Institute on Deafness and Other Communication Disorders). We thank Richard Harland (University of California, Berkeley) for Xenopus tropicalis genomic DNA, Chongmin Wang (National Institute of Child Health and Human Development, NIH) for zebrafish, and Kenneth Johnson (The Jackson Laboratory) for the $j c^{2}$ allele. We also thank Doris Wu and Dennis Drayna for comments on this manuscript.

Correspondence should be addressed to Konrad Noben-Trauth, 5 Research Court, Rockville, MD 20850. E-mail: nobentk@nidcd.nih.gov.

N. A. Jenkins's and N. G. Copeland's present address: Institute of Molecular and Cell Biology, Singapore 138673, Singapore.

Z. Chen's present address: Department of Neurosurgery, University of Maryland School of Medicine, Baltimore, MD 21201.

D0I:10.1523/JNEUROSCI.1280-08.2008

Copyright $\odot 2008$ Society for Neuroscience $\quad 0270-6474 / 08 / 286633-09 \$ 15.00 / 0$
}

because the molecular factors that regulate this transformation are largely unknown (Kelley, 2006). Recently, it was suggested that the cochlear growth may involve convergent extension mechanisms because most of the elongating morphological changes involve postmitotic cells, occur in the absence of significant apoptosis, and are accompanied by a successive thinning of the sensory epithelium (Chen et al., 2002). In the mammalian cochlea, convergent extension and planar cell polarity (PCP) pathways share common factors, because mutations in Vangl2, Wnt5a, and $D v l 1^{-1-} D v l 2^{-1-}$ double mutants cause shortening of the cochlea and orientation defects of the stereociliary bundle (Montcouquiol et al., 2003; Wang et al., 2005; Qian et al., 2007). Other studies, however, suggest that cochlear elongation and convergent extension pathways only partially overlap, because mice deficient for the transcription factors Pou3F4, forkhead box G1 (Foxg1), and neurogenin1 (Neurog1) exhibit a cochlear growth defect in the absence of significant hair cell PCP defects (Phippard et al., 1999; Ma et al., 2000; Pauley et al., 2006).

The genetic analyses of spontaneous and induced mutations in the mouse model system provided valuable insights in developmental mechanisms and physiological properties of sensory hair cells in the organ of Corti (Steel and Kros, 2001; Frolenkov et al., 2004; Brown et al., 2008). Jackson circler ( $j c)$ is a recessive mutation that arose spontaneously on the C57BL/6J background in 1963, causing erratic circling behavior and hyperactivity (Southard, 1970). Jc homozygous mutants have a significant 
hearing deficit at 8 weeks of age with elevated hearing thresholds at the $16 \mathrm{kHz}$ stimulus of $86 \pm 8 \mathrm{~dB}$ sound pressure level (SPL) compared with $+/ j c$ mice, which show normal thresholds of $12 \pm$ $3 \mathrm{~dB}$ SPL. Hearing loss in $j c$ mutants is preceded by the abrupt halt of the growth of the cochlear duct at E13.5, resulting in a shortened cochlea (Calderon et al., 2006). The $j \mathrm{c}^{2 J}$ allele arose spontaneously in the B6.129S6-Il6 ${ }^{\text {tmIKopf }}$ strain; homozygotes exhibit a circling phenotype and at 6 weeks of age show a mild hearing loss, with hearing thresholds of $43 \pm 11 \mathrm{~dB}$ SPL compared with normal thresholds of $15 \mathrm{~dB}$ SPL in $+/ j c^{2 J}$ heterozygotes. In this article, we identified the vertebrate homolog of Drosophila sine oculis-binding protein (Sobp) in the jc locus, which we named $J x c 1$, and we present evidence for a role of $J x c 1$ in cochlear growth, cell fate, and patterning of the organ of Corti.

\section{Materials and Methods}

Mice. Mice were obtained from The Jackson Laboratory. The $j c$ mutation arose in 1963 on the C57BL/6J background and is designated C57BL/6J$j c / J$ (stock \#563). The $j c^{2 J}$ mutation arose spontaneously in the B6.129S6Il6 ${ }^{\text {tm1Kopf }}$ colony (stock \#2650) and was given the official strain name B6(129S6) $-j c^{2 J} / \mathrm{J}$ (stock \#5292). Animal studies were conducted under National Institutes of Health-approved animal study proposals.

Gene identification. Brain cDNA from C57BL/6J-+/jc and C57BL/6J$j c / j c$ mice was amplified with primers specific for $J x c 1$, and products were sequenced. C57BL/6J-+/jc heterozygotes $(n=15)$ and C57BL/6J-jc/jc homozygotes $(n=20)$ used for mutation analyses were classified according to their auditory brainstem response profile. B6(129S6) $-j c^{2 J} / j c^{2 J}$ were phenotyped based on their cochlea malformation at postnatal day 12 (P12)-P14. Control inbred strains included C57BL/6J, CAST/Ei, CZECHII/Ei, A/J, AKR/J, DBA, FVB/NJ, MOLF/Ei, and NIH Swiss. Human genomic DNA was purchased from Clontech Laboratories. Rat and chicken genomic DNA was purchased from Seegene. Rhesus genomic DNA was obtained from BioChain Institute, Takifugu rubripes genomic DNA was obtained from Genservice, and Anopheles gambiae flies were obtained from American Type Culture Collection (ATCC). The sequences of the zebrafish orthologs $J c x 1-A$ and $J x c 1-B$ and Anopheles gambiae were deduced from cDNA derived from adults. GenBank accession numbers are as follows: mouse (Mus musculus), DQ157775; human (Homo sapiens), DQ507800; chicken (Gallus gallus), DQ503407; rat (Rattus norvegicus), DQ503410; Xenopus tropicalis, DQ503412; zebrafish (Danio rerio), Jxc1-A, DQ655703 and Jxc1-B, DQ503413; Drosophila melanogaster, DQ655701; Anopheles gambiae, DQ655702.

Histology. Temporal bones were removed, and inner ears were dissected in PBS, perfused with 4\% paraformaldehyde, and kept in the same fixative at room temperature for at least $12 \mathrm{~h}$. Inner ears were washed twice in PBS, decalcified in 0.1 M EDTA, pH 8.0, in PBS for 3 weeks, and then dehydrated with a graded series of ethanol, infiltrated with JB-4 polymer (Polysciences), and embedded. Serial sections were cut at $4 \mu \mathrm{m}$ thickness on a RM2265 microtome (Leica), stained with $0.1 \%$ toluidine blue O, imaged on a DM5000B microscope (Leica), and photographed with a DFC500 digital camera (Leica).

Latex paint injection. Dissection and preparations of paint-fill injections were performed as described following the protocol of Martin and Swanson (Martin and Swanson, 1993; Calderon et al., 2006).

RNA in situ hybridization. A 1350 bp PCR product corresponding to nucleotide position 191-1541 of $J x c 1$ was amplified using the IMAGE cDNA clone 5704623, cloned into pBluescript, and labeled using the DIG RNA Labeling kit (Roche Molecular Biochemicals). Frozen sections of mouse embryos and cochleae were processed for in situ hybridization as described previously ( $\mathrm{Wu}$ and $\mathrm{Oh}, 1996)$. Briefly, mouse embryos or cochlear ducts of neonates were harvested, fixed in $4 \%$ paraformaldehyde, dehydrated in 30\% sucrose, and embedded in OCT compound (Tissue-Tek). Twelve-micrometer sections were cut on a LEICA CM3050S cryostat, warmed to room temperature, rehydrated, postfixed, and permeabilized using $10 \mu \mathrm{g} / \mathrm{ml}$ proteinase $\mathrm{K}$. Hybridization was performed in $50 \%$ formamide, $5 \times \mathrm{SSC}, 1 \% \mathrm{SDS}, 50 \mu \mathrm{g} / \mathrm{ml}$ heparin, and 50 $\mu \mathrm{g} / \mathrm{ml}$ yeast RNA at $70^{\circ} \mathrm{C}$ overnight in Seal-A-Meal bags at a probe concentration of $\sim 0.2 \mu \mathrm{g} / \mathrm{ml}$. Slides were washed, incubated with antidigoxigenin antibody overnight at $4^{\circ} \mathrm{C}$, and developed in NBT (nitroblue-tetrazolium-chloride) plus BCIP (5-bromo-4-chloro-indolylphosphate) for $4 \mathrm{~h}$ at room temperature.

Phalloidin staining and immunofluorescence. Whole-mount cochlear ducts were fixed in 4\% paraformaldehyde and processed as described previously (Montcouquiol et al., 2006). Antibodies used were as follows: anti-myosin VI (1:200; Sigma); anti-Prox1 (1:1000; Covance); antip75 ${ }^{\text {NTR }}$ (1:1000; Millipore Bioscience Research Reagents); and antiS100A1 (1:100; DAKO). Secondary antibodies and labeled phalloidin were from Invitrogen. Images were acquired with a LSM510 Zeiss microscope, and a DM6000 Leica microscope and MetaMorph software.

Transfections and immunostaining. $\mathrm{Pb} 544$ is a rabbit polyclonal antiserum raised against the synthetic peptide PPENKRSRKPAHPVKR located at the amino acid position $10-25$ of the mouse Jxc1 protein. Cos 1 cells (ATCC) were transiently transfected using GeneJuice Transfection Reagent (Novagen) as recommended by the manufacturer. Forty-eight hours after transfection, cells were fixed in $4 \%$ paraformaldehyde (Sigma), blocked in 3\% BSA, and incubated in Pb544 diluted 1:100 in 3\% BSA for $1 \mathrm{~h}$ at room temperature. After three washes, cells were stained with the secondary antibody, washed, and mounted in ProLong Gold antifade reagent with $4^{\prime}, 6^{\prime}$-diamidino-2-phenylindole (DAPI; Invitrogen).

Real-time PCR expression profiling. Mouse cDNA MTC panel I and MTC panel II were obtained from Clontech Laboratories. Approximately 2 ng of cDNA was used in a $25 \mu \mathrm{l}$ reaction using the $2 \times$ SYBR Green Master Mix from Applied Biosystems, amplified, and analyzed using an OPTICON MJ Research. Gapd- $f$, 5'-ATGGTGAAGGTCGGTGTGAAC-3'; Gapd-r, 5' GAGTCTACTGGTGTCTTCACC-3'. Jxcex2f, , 5'-GGCTGGTATGGCTATGATAAAG-3'; Jxcex4r, 5'-TGACACATCATCTTCTGCTG-3'. Cycling conditions: initial denaturation, $95^{\circ} \mathrm{C}, 10 \mathrm{~min}$, then $95^{\circ} \mathrm{C}, 15 \mathrm{~s}, 60^{\circ} \mathrm{C}$, $60 \mathrm{~s}$, followed by plate read ( 50 cycles). Each cDNA was tested with Gapdh and $J x c 1$ primer pairs in six independent experiments. To normalize different cDNAs, Ct values obtained with $J x c 1$ primer pair were subtracted from $\mathrm{Ct}$ values obtained with Gapdh primer pair. The normalized Ct value of cochlea cDNA was set as 1 , and the coefficient for each tissue cDNA was computed.

\section{Results}

\section{Truncating mutations of the $J x c 1$ gene at the jc locus}

Using an F2 intercross, we previously localized $j c$ to a $220 \mathrm{~kb}$ genomic region $(0.2 \pm 0.07 \mathrm{cM})$ on proximal chromosome 10 between the markers D10Ntra12 and D10Ntra16; markers D10Ntra14 and D10Ntra15 were concordant with jc in 1980 meioses (Calderon et al., 2006). The $j c$ critical interval contained several predicted exons and the Mus musculus RIKEN cDNA $5330439 \mathrm{J01}$ (also named BC059851), which covered $172 \mathrm{~kb}$ of the genomic region (Fig. 1A). We screened for mutations using brain- and cochlea-derived cDNA from C57BL/6J-jc/jc and B6(129S6) $-j c^{2 J} / j c^{2 J}$ mice. In the $j c$ allele, we identified a $10 \mathrm{bp}$ deletion in exon 6 comprising nucleotides 1346-1355 of the BC059851 coding sequence (1346-1355del; S449fsX490) (Fig. $1 B)$. Resequencing genomic DNA of C57BL/6J-+/jc heterozygotes $(n=15)$ and C57BL/6J-jc/jc homozygotes $(n=20)$ demonstrated a perfect correlation between the genotype and hearing function. The deletion also segregated with the hearing status in the critical recombinants and was absent in nine common inbred strains. In the $j c^{2 J}$ allele, we found a G-to-T transversion occurring at nucleotide position $1894(1894 \mathrm{G}>\mathrm{T})$, converting a glycine codon to a stop codon at amino acid position 632 (G632X) (Fig. 1C). The nonsense mutation segregated with the cochlear malformation $(n=5)$ (see Fig. $4 C$ ) and was not detected in nine inbred strains, including the B6.129S6-Il $6^{\operatorname{tm} 1 \text { Kop } \mathrm{f}}$ strain, on which the mutation occurred. Both alleles are truncating mutations, deleting 48 and $28 \%$ of the protein in $j c$ and $j c^{2 J}$, respectively. In addition, we sequenced 30 predicted exons in the critical interval, 
A

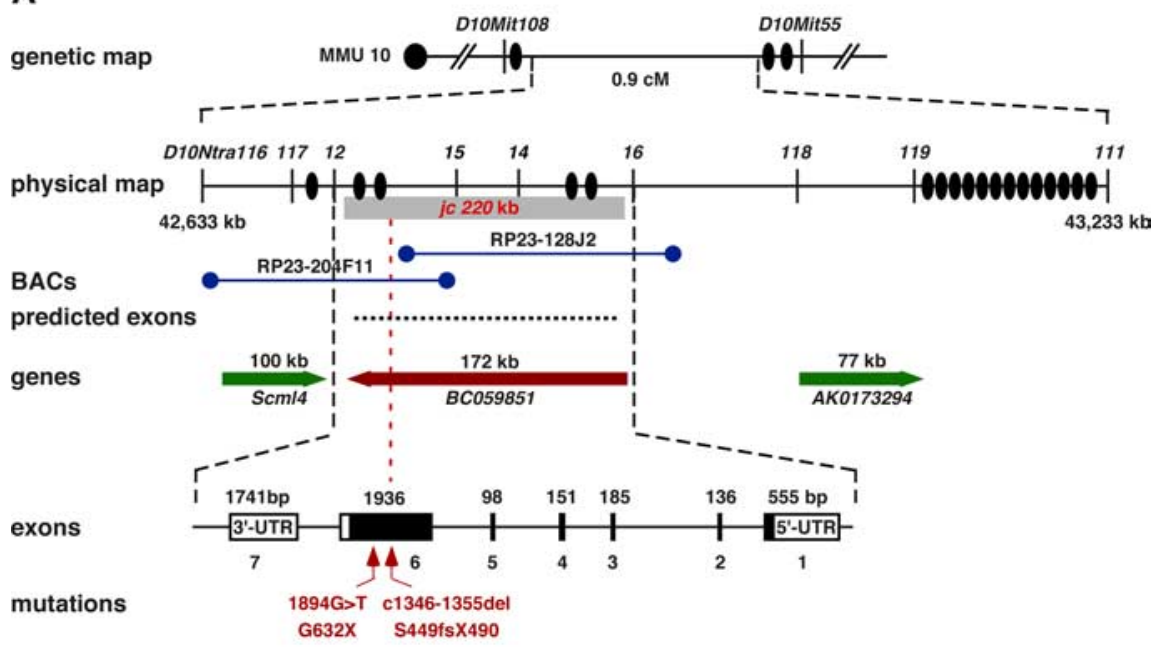

B

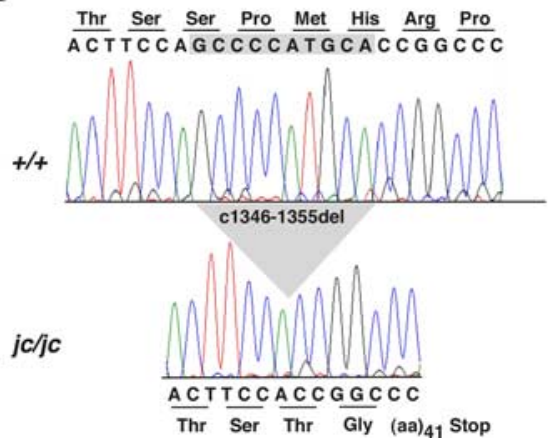

Figure 1. Genetic and physical maps of $j c$ locus. A, From top to bottom is shown the genetic region on chromosome 10 (MMU10) containing the $0.9 \mathrm{CM}$ jc interval defined by markers D10Mit108 and D10Mit55. The physical map shows the location of D10Ntra: markers used for genetic mapping, the approximate location of recombination events (filled oval), and the $220 \mathrm{~kb} j \mathrm{c}$ minimal interval. Physical coordinates obtained from the UCSC Genome Browser (mouse assembly July 2007) are shown on the left and right and given in kilobases. Locations and names of $B A C$ clones used to generate transgenic lines and approximate locations of predicted exons and open-reading frames are shown. Location and size of three genes indicating the direction of transcription are given. $5 \mathrm{~cm} / 4$, Sex comb on midleg-like 4. Intron/exon structure of Jxc 1 (BC059851), coding exons (filled boxes), untranslated regions (UTR), length of exons in base pairs, number of exons (1-7), and location of $j c$ and $j c^{2 J}$ mutations are shown. $B$, Sequencing chromatograms of C57BL/6J-+ / + and jc/jc mutant genomic DNA across the jc mutation in exon 6 . The $10 \mathrm{bp}$ deletion (c1346-1355del) is indicated. C, Sequence traces of a $\left(57 \mathrm{BL} / 6 \mathrm{~J}-+/+\right.$ and an affected $j \mathrm{c}^{2 J}$ mutant mouse. The location of the G-to-T substitution is indicated by an arrow.

but found no nucleotide difference in $+/ j c$ and $j c / j c$ genomic DNA. Transgenic mice harboring BAC clones RP23-204F11 and RP23-128J2, which were introgressed on the C57BL/6J-jc/jc mutant background, did not rescue the $j c$ phenotype, consistent with the location of the $j c$ mutation (Fig. $1 \mathrm{~A}$ ). Together, we conclude that the 10 bp deletion and $1894 \mathrm{G}>\mathrm{T}$ changes are causative mutations and assigned the EST the gene symbol Jxcl (GenBank accession number, DQ157775).

\section{Jxc1 encodes a nuclear FCS-type zinc finger protein}

The $J x c 1$ gene has six coding exons and a seventh exon containing the $3^{\prime}$ - untranslated region. Jxcl is a single-copy gene, and its open reading frame of $2594 \mathrm{nt}$ encodes a protein of 864 aa. Bioinformatics analyses identified two proline-rich sequences (amino acids 346-543 and 695-745), two nuclear localization signals (amino acids 11-18 and 851-858), and two domains that are closely related to the phenylalanine-cysteine-serine (FCS)-type zinc finger proteins (PS51024) (Fig. 2A,B; supplemental Fig. $1 A, B$, available at www.jneurosci.org as supplemental material). The FCS zinc fingers are named after the signature phenylalanine-cysteine-serine (FCS) residues (Zhang et al., 2004) that are present in proteins including Zfp198, lethal(3) malignant brain tumor ( $L 3 m b t l 2)$, the polyhomeotic proteins $P h c 1, P h c 2$, and $P h c 3$, and the Drosophila sex comb on midleg $(\mathrm{Scm})$ protein.

To identify functionally conserved domains, we isolated $J x c 1$ orthologues through sequencing and homology database searches in additional vertebrate species (Xenopus tropicalis, Danio rerio, Tetraodon nigroviridis, Takifugu rubripes, Gallus gallus, and several mammalian species) and insects (Drosophila and Anopheles). The teleost genome contains two copies of Jxc1, named Jxc1-A and Jxc1-B, which are respectively 60 and $37 \%$ similar to the mammalian Jxc1 protein. We could not find $J x c 1$ sequences in nematodes or protozoa. ClustalW alignments of these orthologues identified two highly conserved motifs at amino acids $34-51$ and 520-543 (Fig. 2A; supplemental Fig. $1 C$, available at www. jneurosci.org as supplemental material).

The domain and motif structure indicated that Jxcl is targeted to the nucleus. To test this hypothesis, we constructed green fluorescent protein (GFP)-tagged Jxc1 fusion proteins for expression in COS-1 cells. In transiently transfected cells, the green fluorescence overlapped with the nuclear DAPI staining. Immunostaining with a polyclonal antibody raised against a Jxc1-specific N-terminal epitope also coincided with the GFP localization, suggesting that the Jxc1-GFP fusion protein resides in the nucleus (Fig. 3). Mutant GFP-tagged isoforms encoding the $j c$ and $j c^{2 J}$ truncation, however, were partially retained in the cytoplasm. This effect was more pronounced for the $j c$ mutant than for the $j c^{2 J}$ isoform.

\section{Supernumerary outer hair cells at the apex in $j c$ and $j c^{2 J}$} cochleae

We previously showed that during embryonic development in $j c$, the abrupt halt of the extension of the cochlea leads to the absence of the apical coil in the mature cochlea (Fig. 4A) (Calderon et al., 2006). We also observed a shortened cochlea in the $j c^{2 J}$ allele, although to a lesser extend than in $j c$ (Fig. $4 B, C$ ). The cochlear duct in $j c / j c$ mutants measured on average $3583 \pm 156 \mu \mathrm{m}$, which is a $28 \%$ reduction from the average length of the wild-type cochlear duct $(4921 \pm 262 \mu \mathrm{m})$. Cross sections of $j c / j c$ cochlear ducts showed the presence of an additional row of outer hair cells (OHCs) in the midapical region and a severe disruption of the regular pattern with many more rows of OHCs at the apex (Fig. $4 D-F)$. In addition, beginning in the midapical region of some $j c$ cochleae, the lateral region of the organ of Corti appeared to contain ectopic inner hair cells (IHCs) and a second tunnel of Corti. In some regions, this resulted in an apparent mirror-image duplication of the organ of Corti (Fig. 4E).

To more fully characterize the morphological defects, co- 
A

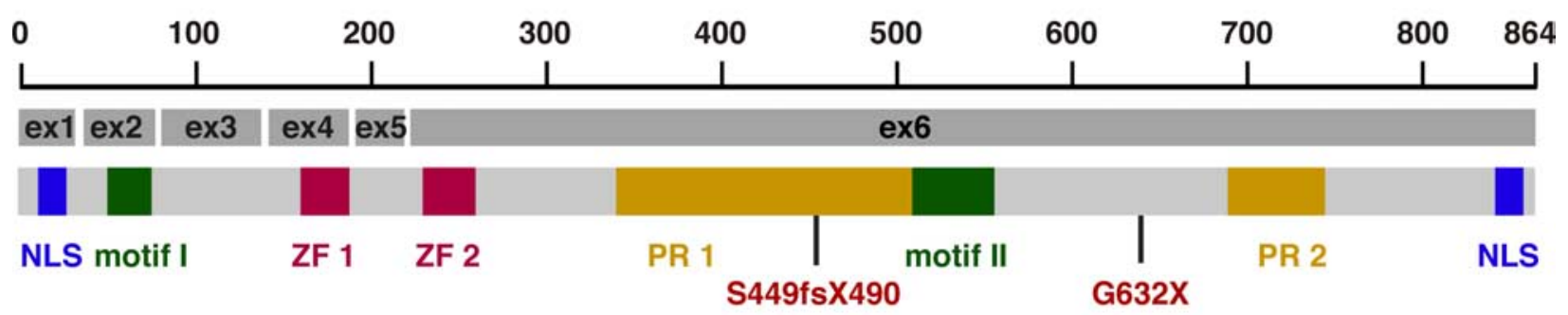

B

\begin{tabular}{|c|c|}
\hline JXC1 ZF1 & I \\
\hline JXC1 ZF2 & LVCDWCKH I RHTKEYLDFGDGERRLQFCSAKCLN \\
\hline L3MBTL2 & AVCEMCGIVGTREAFFS-----KTKR̃FCSVSCSR \\
\hline PHC1 & LKCEYCGKYAPAEQFR------GSKRFCSMTCAK \\
\hline PHC2 & LKCELCGRVDFAYKFK------RSKRFCSMACAK \\
\hline PHC3 & LKCEFCGKMGY PNEFL------RSKRFCTMSCAK \\
\hline SCM & ATCTWCGEGKLPLQYVLPTQT-GKKEFCSETCIA \\
\hline ZFP 1 & VTCANCKKPLQKGQTAYQRKGS-AHLFCSTTCLS \\
\hline
\end{tabular}

Figure 2. Domain and motif structure of Jxc1. A, A schematic diagram shows location of exons, mutations, motifs, and domains of Jxc1. NLS, Nuclear localization signal; ZF, zinc finger; PR, proline-rich region. $j$ c and $j \mathrm{c}^{2 J}$ mutations are indicated in red. The scale bar is in amino acids. The Jxc 1 GenBank accession number is DQ157775. $\boldsymbol{B}$, Shown is a ClustalW alignment of the predicted zinc finger regions. Conserved cysteine $(C)$ and FCS residues are highlighted in blue and red, respectively. A hyphen indicates a gap in the sequence. An asterisk indicates a conserved residue. ZF1, Zinc-finger domain 1 of JXC1; L3MBTL2, human I(3)mbt-like 2 (GenBank accession number Q969R5); PHC1-PHC3, mouse polyhomeotic-like 1-3 (GenBank accession numbers Q64208, Q90WH1, and Q8CHP6, respectively), SCM, mouse sex-comb on midleg (GenBank accession number Q9VHA0); and ZFP198, human Zfp198 (GenBank accession number CAH7013).

chleae from $j c$ and $j c^{2 J}$ mutants were analyzed in surface preparations. Staining with the S100A antibody (a marker for IHC) or with a myosin VI antibody (a marker for differentiated hair cells) and phalloidin (a marker for stereociliary hair bundles) revealed that up to midbase, the pattern of the sensory epithelium was relatively normal in $j c$. However, around midbase, we observed short stretches of epithelium with two, instead of three, rows of OHCs (Fig. 4G,H), and a fourth row of OHCs generally appeared (Fig. 4I), followed by an increasingly severe disruption of the pattern of the sensory epithelium toward the apex (Fig. $4 J$ ). Many additional $\mathrm{OHCs}$ were observed in the more apical portion of the duct, forming up to five and six rows. Furthermore, many hair cells, particularly at the most outer edge of the epithelium, had severe planar polarity defects. A similar disruption of the cellular pattern was observed in the $j c^{2 J}$ mutant, with a fourth row of outer hair cells appearing at the midapical region and up to eight rows of outer hair cells developing at the very apex (Fig. $4 K-M)$.

Mirror-image duplications of tunnel of Corti and inner hair cells

To determine whether supernumerary OHCs were supported by Deiter's cells, we stained jc/jc cochleae with S100A1 (a marker for Deiter's cells) and found that there was a normal ratio between OHCs and Deiter's cells (Fig. 5A). Staining with Prox1, a marker of the pillar and Deiter's cells (Bermingham-McDonogh et al., 2006), showed

B
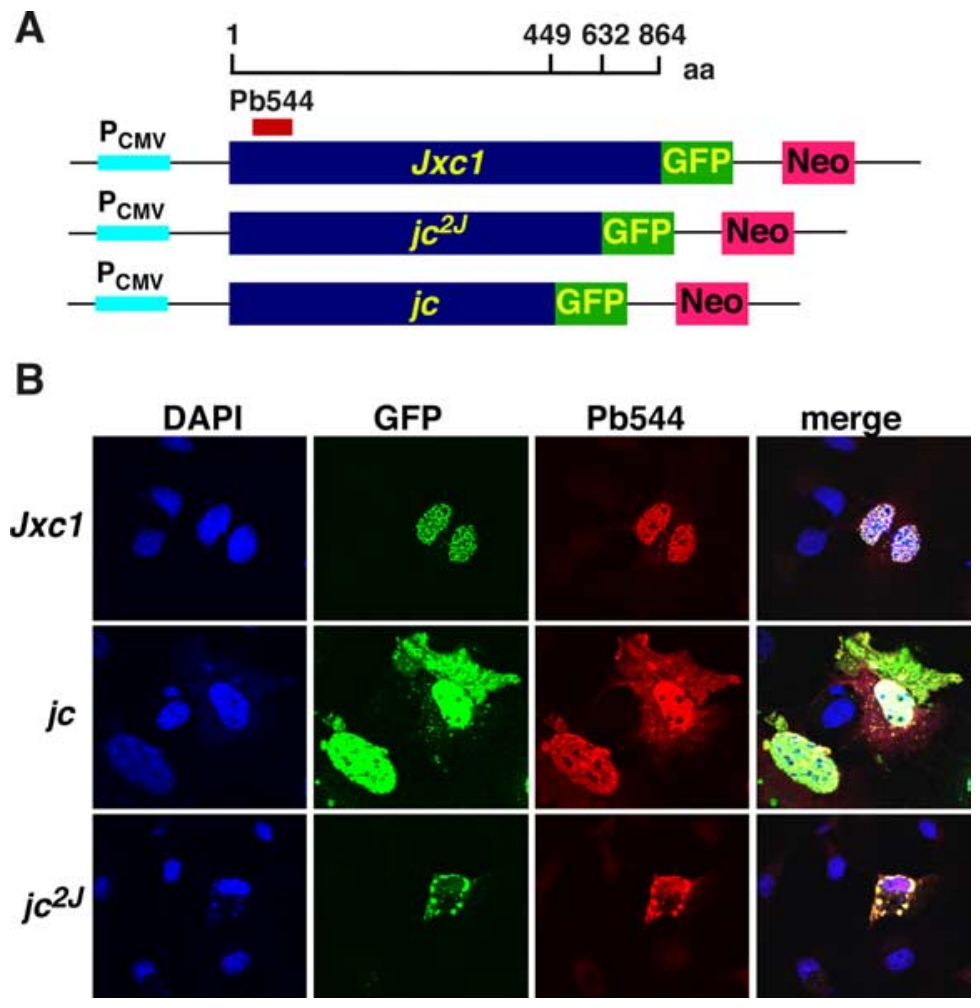

Figure 3. Jxc1 is targeted to the nucleus. $A$, Diagram depicting schematically the design of the fusion proteins and the location of the Jxc1 epitope. $\boldsymbol{B}$, COS cells after transfection with GFP-tagged wild-type Jxc1 protein and mutant constructs expressing the $j c$ and $j c^{2 J}$ truncated GFP fusion protein. Fixed COS cells were also stained with antibody against Jxc1 (Pb544). Nuclei appear in blue, the GFP domain is shown in green, and the antibody staining is shown in the red channel.

that the supporting cells were also differentiated (data not shown). In addition to labeling Deiter's cells, the S100A1 antibody also serves as a marker to distinguish inner from outer hair cells. Therefore, it was possible to determine whether inner hair 

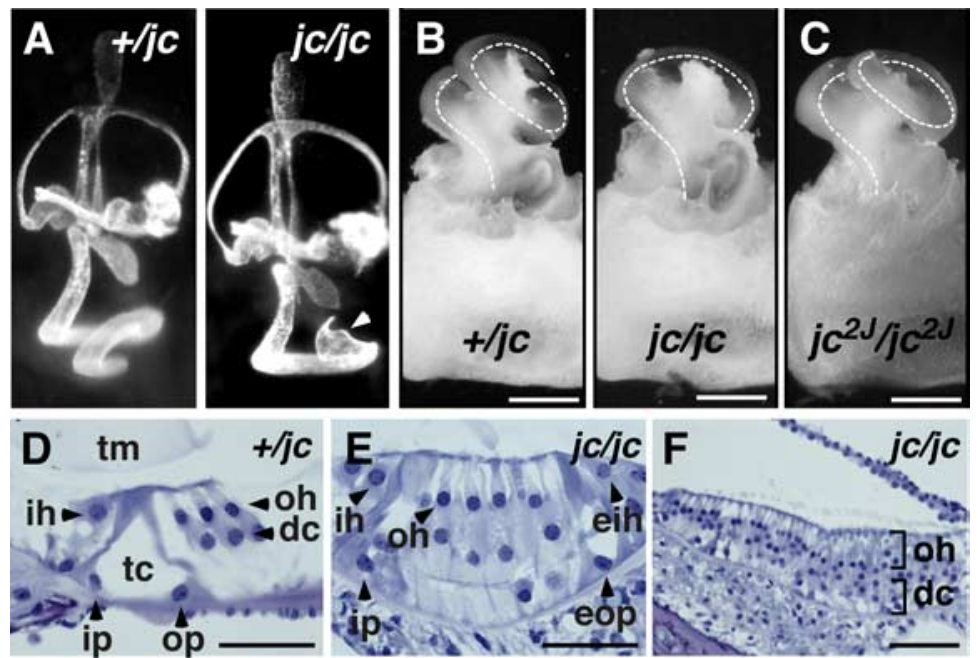

$j c / j c \mathrm{~F}$
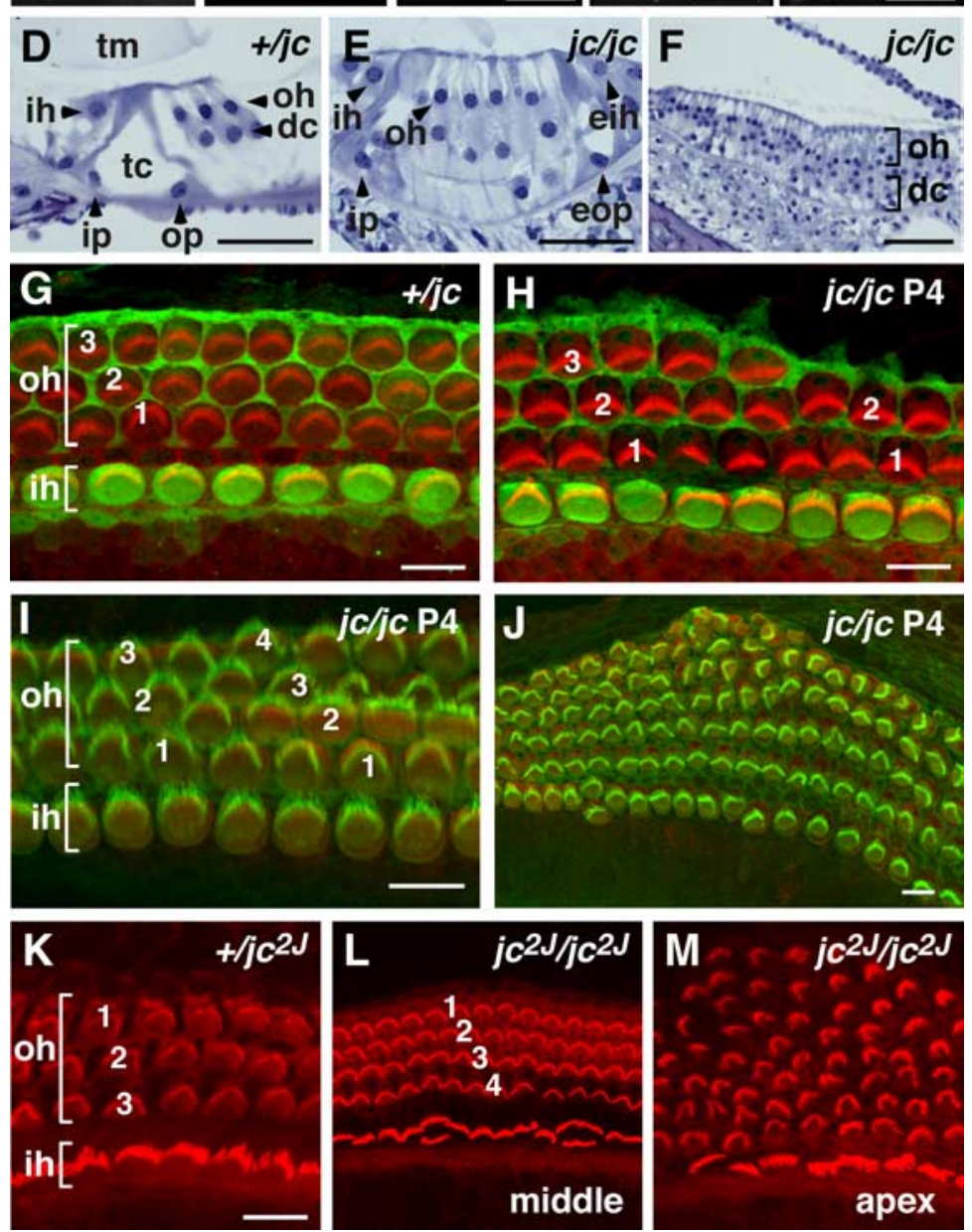

Figure 4. Cochlea dysplasia in $j c$ mutants. $\boldsymbol{A}$, Inner ears injected with latex paint of $+/ j$ c and $j$ c/jc at embryonic day 15.5 . Note the bulbous structure at the apex of the shortened cochlea (arrowhead). B, C, Cochlear ducts from P12 (+/jc, jc/jc) and P14 $\left(j c^{2 J} / j c^{2 J}\right)$ mice are shown. Note that the cochlear duct in the $j c^{2 J}$ mutant is less shortened than in $j c$. The cochlear coil is indicated by the dotted lines. $\boldsymbol{D}-\boldsymbol{F}$, Plastic sections of the organ of Corti stained by toluidine blue 0 are shown. The organ of Corti is normally developed in 3-week-old + /jc mice (D). The locations of IHCs (ih), OHCs (oh), Deiter's cells (dc), inner (ip) and outer (op) pillar cells, tectorial membrane (tm), and tunnel of Corti (tc) are depicted. A section from the midapical region of a jic shows four rows of $\mathrm{OHCS}(\boldsymbol{E})$, an ectopic IHC (eih), and an ectopic outer pillar cell (eop) at the lateral edge. At the apical region, supernumerary rows of OHCs (oh, bracket) and Deiter's cells (dc, bracket) are seen $(\boldsymbol{F}) . \mathbf{G}-\boldsymbol{M}$, Confocal images of organ of Corti surface preparations. Staining with S100A1 (green) and phalloidin shows a normally developed organ of Corti in jc heterozygotes ( $G$ ) with one row of IHCs (ih, bracket) and three rows of OHCs (oh, bracket). At midbase in jc homozygotes, short stretches of only two rows of OHCs appeared $(\boldsymbol{H})$. Staining with an anti-myosin VI antibody (a marker of differentiated hair cells; red) identifies four rows of $0 \mathrm{HCs}$ at the midapical region and up to six rows of $\mathrm{OHCs}$ at the more apical region $(\boldsymbol{J})$. Phalloidin staining (red) of $j \mathrm{C}^{2 J}$ organ of Corti shows four rows of $\mathrm{OHCS}$ at the midapical region (compare $+/ j \mathrm{c}^{2 J}$ with $\mathrm{jc}^{2 J} / j \mathrm{C}^{2 J} ; \boldsymbol{K}, \boldsymbol{L}$ ) and a disorganized pattern of $0 \mathrm{HC}$ at the apex $(\boldsymbol{M})$. Scale bars: $\boldsymbol{A}-\mathbf{C}, 500 \mu \mathrm{m} ; \boldsymbol{D}-\boldsymbol{F}, 50 \mu \mathrm{m} ; \boldsymbol{G}-\boldsymbol{K}, 10 \mu \mathrm{m}$.

cells were present on the lateral edge of the organ of Corti. In apical regions of $j c$ mutant cochleae, ectopic hair cells located on the lateral edge are labeled with anti-S100A1, confirming the identity of these cells as inner hair cells (Fig. 5A-C). To determine whether ectopic pillar cells are also present, $j c$ cochleae were stained with anti-p $75^{\text {NTR }}$ (a marker of pillar cells and Hensen's cells). Cells that are positive for anti-p $75^{\mathrm{NTR}}$ are clearly present on the lateral edge of the organ of Corti (Fig. 5D-H). This p $75^{\text {NTR }}$ labeling was observed starting at the midapical region, and was present, although intermittently, up to the apex, where in some specimens, but not all, the row of ectopic pillar cells seemed to converge with the medial row of pillar cells (Fig. $5 H$ ). However, because the lateral side of the organ of Corti is the normal location of Hensen's cells, we examined the morphological characteristics of the putative ectopic pillar cells on histological sections. Pillar cells have a unique morphology that includes a basal nucleus and a lumenal extension that gives rise to the pillar head, a microtubule-rich structure that appears as a more intense blue in toluidine-blue-O-stained sections (Fig. 5I). Moreover, inner and outer pillar cells combine to form the tunnel of Corti, a triangular, fluid-filled space between the inner and outer hair cells. The organ of Corti in $j c$ cochleae clearly contains a normal, although somewhat immature, tunnel of Corti on its medial side and, in addition, a second, ectopic tunnel of Corti located on the lateral side (Fig. $5 \mathrm{~J}, \mathrm{~K}$ ). The ectopic pillar cells appear very different from comparable Hensen's cells in that the cells extend from the lumenal surface to the basal lamina. In addition, two pillar heads and a rudimentary tunnel are evident (Fig. $5 \mathrm{~K}$ ). These data are consistent with a mirror-image duplication of the tunnel of Corti in the apical regions of $j c$ mutant cochleae.

\section{Ectopic generation of vestibular-like hair cells in Kölliker's organ} In addition to the shortened cochlea and the defects in cellular patterning, the mutation in $J x c 1$ generated ectopic patches of hair cells in all of the $j c / j c$ cochleae we analyzed. We observed groups of ectopic hair cells with an average of $7 \pm 0.8$ patches of various sizes per cochlea $(n=7)$, distributed along the entire length of the duct and located within the Kölliker's organ (Fig. $6 \mathrm{~A}$, inset, arrowheads). We also noted an accumulation of F-actin at the apical surface of the epithelial cells immediately surrounding the hair cells, arranged sometimes in a rosette, a structure that is typically found in the utricle and saccule (Fig. 6B). These ectopic hair cells had stereociliary bundles that were elongated and lacked the typical $\mathrm{V}$ or W shape of OHC; instead they exhibited the typical appearance of vestibular hair bundles (Fig. 6C). Some of these cells expressed markers such as $\mathrm{S100A1}$ and appeared to be innervated by fibers (data not shown). 

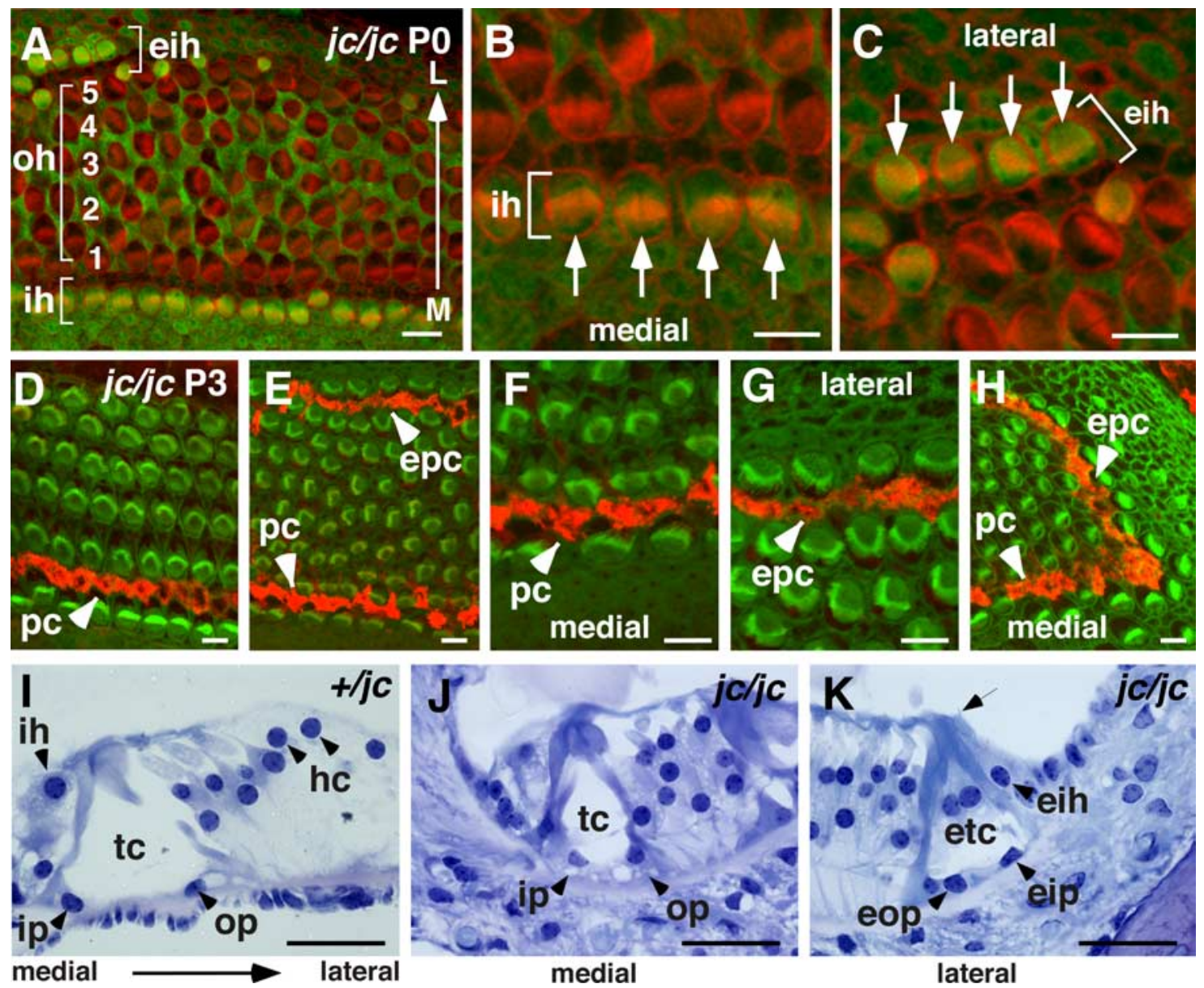

Figure 5. Ectopic tunnel of Corti and inner hair cells. $\boldsymbol{A}-\boldsymbol{H}$, Confocal images of organ of Corti whole-mount preparations. Apical region at age P0 stained for S100A1 (green) and phalloidin (red; A) shows a disorganized pattern of OHC rows (oh, bracket) followed by a stretch if IHCs located ectopically (eih, bracket) at the lateral (L) side of the organ of Corti. Location of IHCs at the medial (M) side is depicted (ih, bracket). $\boldsymbol{B}$, Higher magnification of the medial location of four IHCs (ih, bracket, and arrows). C, The ectopically located IHCs at the lateral side of the organ of Corti (eih, bracket, and arrows). $\boldsymbol{D}-\boldsymbol{H}$, Immunostaining of the midapical $(\boldsymbol{D})$ and apical region $(\boldsymbol{E}-\boldsymbol{H})$ of $j \mathrm{c} / \mathrm{jc}$ at $\mathrm{P} 3$ for p $75^{\mathrm{NTR}}$ (red; phalloidin, green). $\boldsymbol{D}-\boldsymbol{F}$, Location of pillar cells at the medial side is indicated (pc, arrowhead). $\boldsymbol{E}$, A row of ectopic pillar cells at the lateral side of the organ of Corti is stained (epc, arrowhead). $\boldsymbol{F}, \boldsymbol{G}$, Higher-magnification images of pc and epc as shown in $\boldsymbol{E}$. I- $\boldsymbol{K}$, Plastic sections stained by toluidine blue $0 . \boldsymbol{I}$, Normal position of IHCs (ih), inner (ip) and outer (op) pillar cells, tunnel of Corti (tc), and Hensen's cells (hc) in a jc heterozygote. $\boldsymbol{J}, \boldsymbol{K}$, Inj $\mathbf{c}$ mutants, an immature tunnel of Corti i s shown at the medial side $(\boldsymbol{J})$, and ectopic tunnel of Corti (etc) formed by ectopic outer (eop) and inner (eip) pillar cells followed by an IHC is shown at the lateral side (K). Note the stereociliary hair bundle of the ectopic IHC (arrow). Scale bars: $\boldsymbol{A}-\boldsymbol{H}, 10 \mu \mathrm{m} ; \boldsymbol{I}-\boldsymbol{K}, 50 \mu \mathrm{m}$.

\section{Deformed vestibular epithelia in $j c$}

Homozygous $j c$ mice display erratic circling behavior starting at $\sim 5$ weeks of age, suggesting a pathology in the vestibular epithelia. Whole-mount preparations followed by phalloidin staining revealed that the surface area of mutant utricles $(30,864 \pm 3236$ $\left.\mu \mathrm{m}^{2} ; n=4\right)$ and saccules $\left(30,949 \pm 4223 \mu \mathrm{m}^{2}\right)$ was significantly $(p<0.001 ; t$ test) smaller than the corresponding area of wildtype tissue $\left(40,473 \pm 2538\right.$ and $47,494 \pm 4069 \mu \mathrm{m}^{2}$, respectively) (Fig. $6 D, E$ ). Morphometric analyses of cross sections of the maculae of utricle and saccule also showed that mutant utricles $(0.89 \pm 0.09 \mathrm{~mm})$ and saccules $(0.49 \pm 0.02 \mathrm{~mm})$ were significantly thicker $(p<0.05 ; t$ test $)$ than the respective area in heterozygous utricle and saccule $(0.69 \pm 0.03$ and $0.31 \pm 0.01 \mathrm{~mm}$, respectively) (Fig. $6 \mathrm{~F}-\mathrm{H}$ ).

\section{$J x c 1$ expression in sensory epithelia and ganglia}

To correlate the $j c$ phenotype with $J x c 1$ expression, we performed RNA in situ hybridization on inner ears at embryonic and postnatal stages. The lunatic fringe gene ( $L f n g$ ) was used as marker to identify the sensory regions in the cochlea (Morsli et al., 1998) (Fig. 7G). Jxc1 expression was observed at E15.5 in the region of the cochlear sensory epithelium, the spiral ganglia (Fig. 7A), and the cristae ampullaris (data not shown). At P0 and P6, Jxc1 expression was sustained in the sensory epithelium, particularly in the lesser and greater epithelial ridge and in the region of the organ of Corti including sensory and supporting cells (Fig. $7 B-$ $E$ ). At $\mathrm{P} 0$ and $\mathrm{P} 6, J x c 1$ was also expressed in the spiral ganglia, the sensory and supporting cells of the macula of utricle, and cristae ampullaris (Fig. $7 B, C, F$ ) and macula of saccule (data not shown). Diffuse expression was also observed in the stria vascularis at P6 (Fig. 7E). Jxc1 was not expressed in E9.5 otocyst (data not shown), suggesting that it is not involved in the early ventral and dorsal specification of the inner ear.

$J x c 1$ also is expressed in tissues outside the inner ear. Most notably, we found $J x c 1$ expression in the developing retina at E15.5, where expression was confined to the inner nuclear layer, which gives rise to the neuronal layer in the adult retina (Fig. $7 \mathrm{H}$ ). There was also strong expression in the trigeminal ganglion first noticed at E13.5 and present at all later time points (Fig. 7I). In addition, $J x c 1$ was expressed in cells surrounding the dermal papilla of developing hair follicles (Fig. $7 J$ ) and in the olfactory epithelium (Fig. $7 \mathrm{~K}$ ). No hybridization signal was obtained with a Jxcl sense probe (Fig. $7 L$ ).

In the adult, $J x c 1$ showed a broad expression profile (Fig. 

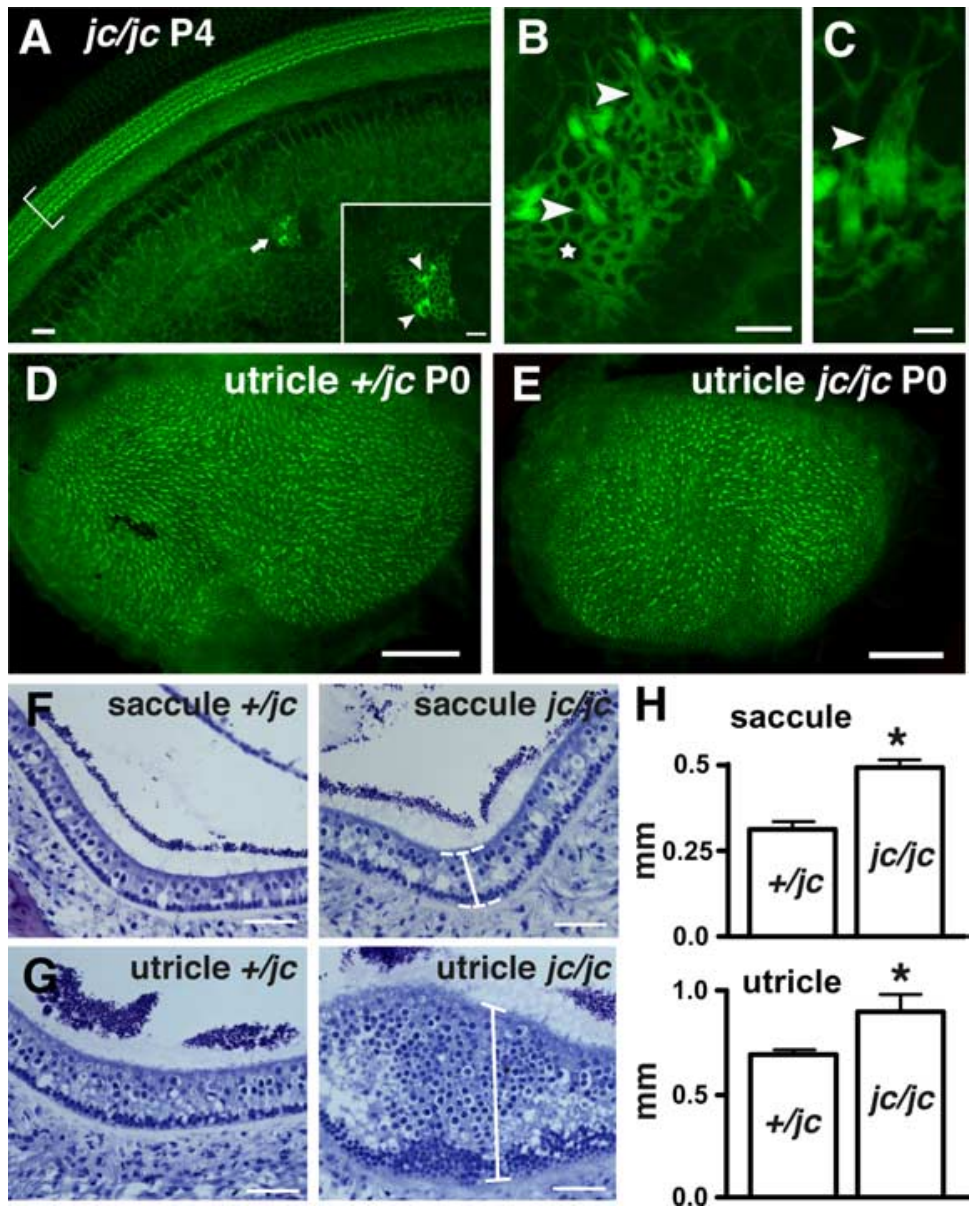

Figure 6. Vestibular-like hair cells in Kölliker's organ. $A$, A low-magnification view of organ of Corti (bracket) and a group of ectopic hair cells in Kölliker's organ (arrow, inset) stained with phalloidin. $\boldsymbol{B}$, A high-magnification view of a patch of ectopic hair cells in the Kölliker's organ. Note the vestibular-like stereociliary hair bundle (arrowheads), the accumulation of F-actin at the apical surface, and the rosette-like formation of cells (star). C, A higher magnification of a hair cell depicts the stereociliary hair bundle reminiscent of vestibular hair cells (arrowhead). $\boldsymbol{D}, \boldsymbol{E}$, Phalloidin stainings of utricle $+/ j c(\boldsymbol{D})$ and jc/jc $(\boldsymbol{E})$ at P0.F, $\boldsymbol{G}$, Toluidine-stained plastic sections of $+/ j$ c and $j c / j$ c saccule $(\boldsymbol{F})$ and utricle $(\boldsymbol{G})$ are shown. Brackets indicate the thickening of the neuroepithelium. $\boldsymbol{H}$, The graph shows the mean \pm SEM thickness of the macule of saccule and utricle of $j$ c heterozygous and homozygous mutants. The asterisk denotes a significant difference ( $p<0.05 ; t$ test). Ten representative sections from three $+/ j$ c and two jc/jc ears were measured. Scale bars: $\boldsymbol{A}, \boldsymbol{B}, 10 \mu \mathrm{m} ; \boldsymbol{C}, 5 \mu \mathrm{m} ; \boldsymbol{D}, \boldsymbol{E}, 50 \mu \mathrm{m} ; \boldsymbol{F}, \mathbf{G}, 300 \mu \mathrm{m}$.

$8 A, B)$. We found $J x c 1$ mRNA in all major tissues tested, albeit at different levels. Relative to mRNA levels in the cochlea, Jxc1 expression was strongest in the brain $(1.03 \times)$, followed by testis $(0.84 \times)$ and eye $(0.76 \times)$; expression was weakest in prostate $(0.44 \times)$ and liver $(0.44 \times)$. Quantitative comparison by real-time PCR showed no significant difference in mRNA levels $(p>0.05$; $t$ test) between normal and $j c$ mutant cochlea- and brain-derived cDNA (Fig. 8C).

\section{Discussion}

In this study, we positionally cloned the $j c$ locus and show that truncating mutations in $J x c 1$ create a unique combination of phenotypes during cochlear development. Several lines of evidence indicate that the detected nucleotide changes in $J x c 1$ are causative mutations. First, a 10 bp deletion and a nonsense mutation in two independent alleles are predicted to truncate the protein; second, the $j c$ and $j c^{2 J}$ mutations perfectly correlated with hearing function and cochlear malformation and were absent in a number of inbred strains; third, no other nucleotide change was found in the coding and noncoding sequence of $J x c 1$ or other predicted exons in the $j c$ interval.

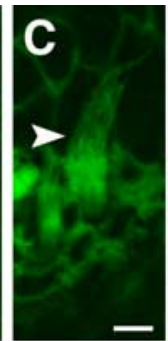

The $j c$ mutation is associated with a shortened cochlea, supernumerary hair cells, mirror-image duplications of organ of Corti, and the presence of ectopic hair cells in Kölliker's organ. In $j c$, the stereocilia hair bundle of some OHCs is severely disoriented, but at most IHCs and OHCs along the cochlear duct, the hair bundle was properly oriented and looked structurally well organized. A shortened cochlea with supernumerary apical hair cells is frequently observed in mutations causing PCP defects. It remains to be tested whether the PCP defect is a direct consequence of reduced Jxcl function or is simply a concomitant appearance of the failure of the cochlea to grow. Our in situ hybridization data show that Jxcl transcription overlaps with the elongation of the cochlear duct (McKenzie et al., 2004). Although the shortening of the cochlea by $\sim 28 \%$ is similar to the result of mutations in planar polarity proteins such as Vangl2 ${ }^{L p}$ or Celsr1 ${ }^{\text {Scy }}$ (Curtin et al., 2003; Montcouquiol et al., 2003), the planar polarity defects in these latter mutants were also expressed in portions of the sensory epithelium that had an otherwise normal cellular pattern. In $j c$ mutants, the planar polarity defects occurred only in those apical regions of the cochlea with the most severe patterning defects. This suggests that the PCP defects in $j c$ might be secondary to the elongation deficiency.

A shortened cochlea with abundant apical outer hair cells is also a phenotypic hallmark of the Foxg1 $1^{\text {tm1M }}$ and Neurog $1^{\text {tmlAnd }}$ mutant cochlea (Ma et al., 2000; Pauley et al., 2006). However, both null mutants exhibit pathologies not observed in $j c$ such as absent sensory neurons (Neurog $\left.1^{\text {tm1And }}\right)$ and abnormal semicircular canals $\left(\right.$ Foxg $\left.1^{t m 1 M}\right)$. The function of Neurogl during cochlear elongation and that of Foxg1 during telencephalic neurogenesis was recently linked to cell-cycle control and proliferation (Martynoga et al., 2005; Matei et al., 2005). Jxc1 expression coincides with the period during which the organ-of-Corti-forming cells become postmitotic (E12-E14) (Ruben, 1967). This phenotypic overlap suggests that $\mathrm{Jxc}$ function may intersect with pathways governing the transition to the postmitotic state of hair cells and supporting cells.

The mirror-image duplication with the ectopic tunnel of Corti and IHC at the apical region is a unique characteristic of the $j c$ phenotype. Whether the appearance of these ectopic cells is the result of de novo specification or attributable to massive cell movements at the constraint apex is not immediately apparent. The convergence of ectopic and naive rows seems to argue that cells are moved around the truncated apex. However, this convergence is not seen in all samples, suggesting ectopic differentiation. Such ectopic differentiation seems to occur unambiguously in the Kölliker's organ by the formation of vestibular-like hair cells. This suggests that Jxc1 may play a role in cell fate, perhaps by silencing target genes required for hair cell specification. Jxc1 expression in the entire cochlear epithelium, including 
inner and outer sulcus, is consistent with this hypothesis. A role for $J x c 1$ in repressing transcription is supported by the predicted motif and domain structure, in particular by the presence of the FCS zinc finger domains. These zinc fingers are present in SCM and PHC proteins that are part of the PRC1 (polycomb repressive complex 1), which is best known for its role in transcriptional silencing of homeotic genes to maintain segment identity in Drosophila (Pirrotta et al., 2003; Lund and van Lohuizen, 2004; Ringrose and Paro, 2004). The FCS zinc finger domain of mouse PHC1 (also known as Rae28) was recently shown to bind DNA and RNA in a non-sequence-specific manner (Zhang et al., 2004), suggesting a similar DNA- and/or RNA-binding activity of Jxc1. We speculate that the sequence specificity might be conferred by the unique Jxc1 motif I and/or motif II.

A role for $J x c 1$ in cell fate and patterning of the organ of Corti is also suggested by the function of its Drosophila homolog Sobp during eye development. Sobp was identified in a yeast two-hybrid screen interacting with the Six domain of the sine oculis (SO) protein (Kenyon et al., 2005). In Drosophila, ectopic expression of Sobp leads to structural aberrations in the adult eye, and it was suggested that Sobp forms a complex with the transcription factors Eyal and SO (Kenyon et al., 2005). In mammals, Sixl, a vertebrate homolog of sine oculis, interacts with Eyal to control the patterning of the otic vesicle (Zheng et al., 2003; Ruf et al., 2004). Given that the Six1 and Jxc1 show overlapping expression pattern in the inner ear at E15.5, it is conceivable that Jxc1 acts as cofactor in the Six1/Eyal pathway.

Hearing loss, cochlear malformation, and the retention of mutant isoform in the cytoplasm are less pronounced in the $j \mathrm{c}^{2 J}$ allele than in $j c$. These phenotypic differences seem to correlate with the location of the mutations in the gene, such that the $10 \mathrm{bp}$ deletion in $j c$ truncates motifs that are otherwise present and presumably functional in the $j c^{2 J}$ mutant. Because the $j c$ isoform still retains the $\mathrm{N}$-terminal nuclear localization signal, motif I, part of the proline-rich region, and the two FCS zinc finger domains, it is possible that $j c$ might represent a hypofunctional allele. This is supported by the observation that Jxc1-expressing tissues such as the retina and olfactory epithelium appear morphologically normal in $j c$ mutants (data not shown). Furthermore, $j c$ homozygotes have a normal life span and reproduction, despite $J x c 1$ mRNA expression in all major adult tissues.

Auditory brainstem response measurements on young $j \mathrm{c} \mathrm{mu-}$ tants showed a considerable variation of thresholds, ranging from 65 to $100 \mathrm{~dB}$ SPL with a mean threshold at the click stimulus of $83 \pm 11 \mathrm{~dB}$ SPL (Calderon et al., 2006). The hearing impairment is on average more severe at the higher than at the lower frequencies and does not change significantly with age. The absence of distortion-product-otoacoustic emissions ( $\mathrm{f}_{2}$ frequency range, $7-50 \mathrm{kHz}$ ) at $75 \mathrm{~dB}$ SPL is consistent with a loss of outer hair cell function along the entire cochlear duct. Although loss of acoustic responsiveness at lower frequencies can be explained by the patterning defects, the hearing loss at higher frequencies seems to be at odds with the relatively normal morphology of the organ of Corti at the base. Possibly the $j c$ mutation has an adverse effect on the stiffness of the organ of Corti. The variability of hearing thresholds on the isogenic C57BL/6J background may be attributable to the hypomorphic nature of the $j c$ allele producing residual protein activity above threshold levels.

Jc mutants also exhibit erratic circling behavior and have no vestibular-evoked potentials (Jones et al., 2005), which is likely the result of the deformed structure of the sensory epithelium of utricle and saccule. This structural deformation is qualitatively and quantitatively similar to the growth defect of the cochlea.

In summary, our study of the jc mutant identifies Jxc1 (synonym Sobp) as a nuclear protein with FCS-type zinc finger domains that is likely involved in transcriptional regulation and reveals a unique combination of developmental phenotypes suggesting that $J x c 1$ controls a critical step during cochlear growth, cell fate, and cellular patterning of the mouse organ of Corti.

\section{References}

Barald KF, Kelley MW (2004) From placode to polarization: new tunes in inner ear development. Development 131:4119-4130.

Bermingham-McDonogh O, Oesterle EC, Stone JS, Hume CR, Huynh HM, Hayashi T (2006) Expression of Proxl during mouse cochlear development. J Comp Neurol 496:172-186.

Brown SD, Hardisty-Hughes RE, Mburu P (2008) Quiet as a mouse: dissecting the molecular and genetic basis of hearing. Nat Rev Genet 9:277-290.

Calderon A, Derr A, Stagner BB, Johnson KR, Martin G, Noben-Trauth K (2006) Cochlear developmental defect and background-dependent hearing thresholds in the Jackson circler (jc) mutant mouse. Hear Res 221:44-58.

Chen P, Johnson JE, Zoghbi HY, Segil N (2002) The role of Math1 in inner 
A

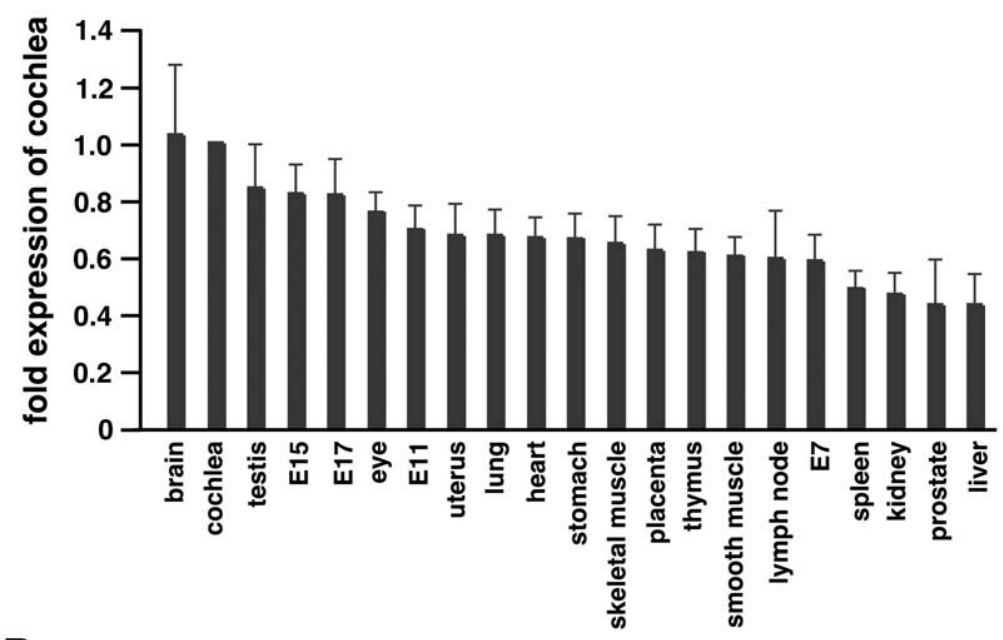

B

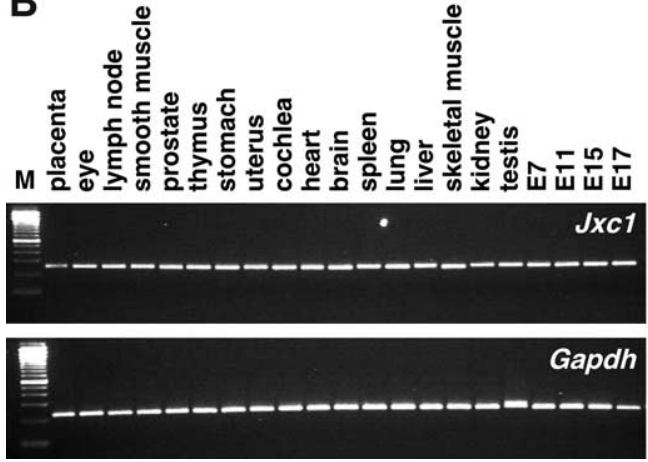

C

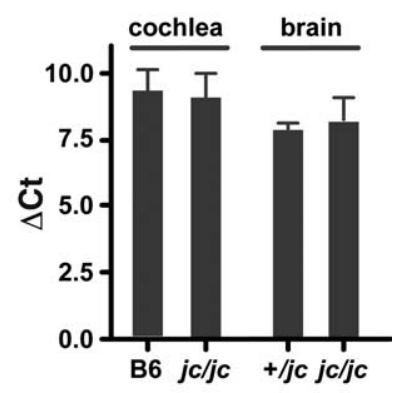

Figure 8. Jxc1 expression profile in adult tissues. $A, J x c 1$ mRNA levels in adult and whole embryo tissue. The histogram shows the expression level of $J x c 1$ in each indicated tissue relative to its level in the cochlea. Bars represent the mean and SD of six real-time PCR amplifications. $\boldsymbol{B}$, Real-time $P C R$ analyses of $J x C 1$ expression in indicated tissues. $M$, Molecular weight marker. One of six representative experiments is shown. C, Quantitative comparison of mRNA levels in cochlea and brain of $\mathrm{C57BL} / 6 \mathrm{~J}$ (B6) and $j$ c heterozygous and homozygous mutants. Bars are mean \pm SEM of at least four tests run in parallel.

ear development: uncoupling the establishment of the sensory primordium from hair cell fate determination. Development 129:2495-2505.

Curtin JA, Quint E, Tsipouri V, Arkell RM, Cattanach B, Copp AJ, Henderson DJ, Spurr N, Stanier P, Fisher EM, Nolan PM, Steel KP, Brown SD, Gray IC, Murdoch JN (2003) Mutation of Celsr1 disrupts planar polarity of inner ear hair cells and causes severe neural tube defects in the mouse. Curr Biol 13:1129-1133.

Frolenkov GI, Belyantseva IA, Friedman TB, Griffith AJ (2004) Genetic insights into the morphogenesis of inner ear hair cells. Nat Rev Genet 5:489-498.

Jones SM, Johnson KR, Yu H, Erway LC, Alagramam KN, Pollak N, Jones TA (2005) A quantitative survey of gravity receptor function in mutant mouse strains. J Assoc Res Otolaryngol 6:297-310.

Kelley MW (2006) Regulation of cell fate in the sensory epithelia of the inner ear. Nat Rev Neurosci 7:837-849.

Kenyon KL, Li DJ, Clouser C, Tran S, Pignoni F (2005) Fly SIX-type homeodomain proteins Sine oculis and Optix partner with different cofactors during eye development. Dev Dyn 234:497-504.

Lund AH, van Lohuizen M (2004) Polycomb complexes and silencing mechanisms. Curr Opin Cell Biol 16:239-246.

Ma Q, Anderson DJ, Fritzsch B (2000) Neurogenin 1 null mutant ears develop fewer, morphologically normal hair cells in smaller sensory epithelia devoid of innervation. J Assoc Res Otolaryngol 1:129-143.

Martin P, Swanson GJ (1993) Descriptive and experimental analysis of the epithelial remodellings that control semicircular canal formation in the developing mouse inner ear. Dev Biol 159:549-558.

Martynoga B, Morrison H, Price DJ, Mason JO (2005) Foxg1 is required for specification of ventral telencephalon and region-specific regulation of dorsal telencephalic precursor proliferation and apoptosis. Dev Biol 283:113-127.

Matei V, Pauley S, Kaing S, Rowitch D, Beisel KW, Morris K, Feng F, Jones K, Lee J, Fritzsch B (2005) Smaller inner ear sensory epithelia in Neurog 1 null mice are related to earlier hair cell cycle exit. Dev Dyn 234:633-650.

McKenzie E, Krupin A, Kelley MW (2004) Cellular growth and rearrangement during the development of the mammalian organ of Corti. Dev Dyn 229:802-812.

Montcouquiol M, Rachel RA, Lanford PJ, Copeland NG, Jenkins NA, Kelley MW (2003) Identification of Vangl2 and Scrb1 as planar polarity genes in mammals. Nature 423:173-177.

Montcouquiol M, Sans N, Huss D, Kach J, Dickman JD, Forge A, Rachel RA, Copeland NG, Jenkins NA, Bogani D, Murdoch J, Warchol ME, Wenthold RJ, Kelley MW (2006) Asymmetric localization of Vangl2 and Fz3 in dicate novel mechanisms for planar cell polarity in mammals. J Neurosci 26:5265-5275.

Morsli H, Choo D, Ryan A, Johnson R, Wu DK (1998) Development of the mouse inner ear and origin of its sensory organs. J Neurosci 18:3327-3335.

Pauley S, Lai E, Fritzsch B (2006) Foxg1 is required for morphogenesis and histogenesis of the mammalian inner ear. Dev Dyn 235:2470-2482.

Phippard D, Lu L, Lee D, Saunders JC, Crenshaw III EB (1999) Targeted mutagenesis of the POU-domain gene Brn4/Pou3f4 causes developmental defects in the inner ear. J Neurosci 19:5980-5989.

Pirrotta V, Poux S, Melfi R, Pilyugin M (2003) Assembly of Polycomb complexes and silencing mechanisms. Genetica 117:191-197.

Qian D, Jones C, Rzadzinska A, Mark S, Zhang X, Steel KP, Dai X, Chen P (2007) Wnt5a functions in planar cell polarity regulation in mice. Dev Biol 306:121-133.

Ringrose L, Paro R (2004) Epigenetic regulation of cellular memory by the Polycomb and Trithorax group proteins. Annu Rev Genet 38:413-443.

Ruben RJ (1967) Development of the inner ear of the mouse: a radioautographic study of terminal mitoses. Acta Otolaryngol Suppl 220:1-44.

Ruf RG, Xu PX, Silvius D, Otto EA, Beekmann F, Muerb UT, Kumar S, Neuhaus TJ, Kemper MJ, Raymond Jr RM, Brophy PD, Berkman J, Gattas M, Hyland V, Ruf EM, Schwartz C, Chang EH, Smith RJ, Stratakis CA, Weil D, et al. (2004) SIX1 mutations cause branchio-oto-renal syndrome by disruption of EYA1-SIX1-DNA complexes. Proc Natl Acad Sci USA 101:8090-8095.

Southard JL (1970) Jackson circler, jc. Mouse News Letters 42:30.

Steel KP, Kros CJ (2001) A genetic approach to understanding auditory function. Nat Genet 27:143-149.

Wang J, Mark S, Zhang X, Qian D, Yoo SJ, Radde-Gallwitz K, Zhang Y, Lin X, Collazo A, Wynshaw-Boris A, Chen P (2005) Regulation of polarized extension and planar cell polarity in the cochlea by the vertebrate PCP pathway. Nat Genet 37:980-985.

Wu DK, Oh SH (1996) Sensory organ generation in the chick inner ear. J Neurosci 16:6454-6462.

Zhang H, Christoforou A, Aravind L, Emmons SW, van den Heuvel S, Haber DA (2004) The C. elegans Polycomb gene SOP-2 encodes an RNA binding protein. Mol Cell 14:841-847.

Zheng W, Huang L, Wei ZB, Silvius D, Tang B, Xu PX (2003) The role of Sixl in mammalian auditory system development. Development 130:3989-4000. 